\title{
Fifteen Years of NASA Student Space Settlement Design Contests: Some Lessons
}

\author{
Al Globus, Ruth Globus, Tugrul Sezen, ${ }^{\ddagger}$ Hami E. Teal, Wenonah Vercoutere, Bryan Yager»
}

\begin{abstract}
I. Abstract
Since 1994, the NASA Ames Research Center has hosted an annual space settlement design contest for 6-12th grade students. Thousands of students and hundreds of teachers from around the world have involved themselves in space settlement, including environmental and life support systems, some devoting months of intense effort. Prize winners now find themselves at Harvard, Stanford, MIT and other top universities, and at least one flew a zero-gravity experiment for the European Space Agency (ESA). Contestants work at home and send their entries to NASA Ames each March. Extensive reference materials are supplied on the web. All entries are judged on a single day by a panel of NASA and contractor scientists and engineers. In 2007, the Ames center director, Pete Worden, was a judge. Many categories are created to generate a large number of winners and every attempt is made to reward entries that show serious effort with some sort of prize. All winners are invited to visit NASA Ames in June. This allows us to meet many of the best contestants and has led to a number of collaborations resulting in published technical papers. ${ }^{1-4}$ The contest is administered by a single, very part time individual, a public school teacher, at a total cost of $\$ 3-6$ per contestant.
\end{abstract}

Key lessons-learned include:

1. A small fraction of students become deeply involved in these projects.

2. A single enthusiastic teacher can make a huge difference.

3. The web can deliver top quality educational materials world-wide at trivial cost.

\section{Introduction}

"In my recent experience with the Space Settlement Design project it became clear that the level of student motivation was miraculous. Many of the student participants became engrossed with the possibilities this subject evoked and in a number of cases study time doubled." Fred Jacques, teacher, Berlin Community School, New Jersey.

In the early 1990s, NASA Ames Research Center began hiring two K-12 teachers each summer to develop aerospace related educational materials. In the beginning, each teacher chose the medium and the message, but the results, while interesting, were ad hoc and unfocused. We looked for a theme to unify the work, a mechanism to involve students directly, and to provide support for teachers to expose their students to aerospace science and engineering.

We found a suitable theme in the ground breaking space settlement summer studies at NASA Ames Research Center and Stanford University. ${ }^{5,6}$ These studies established the feasibility of orbital space settlements. Orbital space settlements are conceived as large, pressurized, rotating spacecraft where thousands

\footnotetext{
*San Jose State University

$\dagger$ NASA Ames Research Center

${ }^{\ddagger}$ Freedom High School

$\S$ NASA Ames Research Center

"NASA Ames Research Center

" Ralston Middle School
} 
of people live, work, and raise their children. This provided an opportunity not only for a wide variety of technical investigations, but students without a strong science background could imagine the interior space, governance models, zero-gravity sports, etc. With the advent of the web at about the same time, we focused the teacher summer work on creating an extensive web site of materials on orbital space settlement ${ }^{\mathrm{a}}$.

\section{Contest}

To involve students directly, the annual NASA Ames Student Space Settlement Design Contest ${ }^{\mathrm{b}}$ was established. The contest is available to 6-12th grade students world wide. Entries are due at NASA Ames each March 31st. Individuals or teams may submit. Entries must be related to space settlement, but there are no other restrictions. While most entries are engineering projects; short stories, art, poetry, and other work are encouraged and have won prizes.

The contest is divided into a number of subcategories where first, second, third and - if appropriate - honorable mention are awarded. Individuals, small teams (six or less) and large teams are in separate categories and 6-9 graders are judged separately from 10-12 graders. There is also a special category for art and for entries with good life science sections. This means we can award prizes to a large fraction of those who have clearly put serious effort into the contest.

The Grand Prize is chosen as the best of all entries and is extraordinarily competitive. Winners often spend six months to a year on their entries and submissions are of extremely high quality. In 2007, the Grand Prize from Ecuador was chosen because a judge recognized the effort as surprisingly similar in kind and quality to their own work! Most of the grand prize winning entries are available on the web site.

Although the work was fairly well funded at the beginning, we believed that a very low-cost approach would have a longer life. This turned out to be correct. To keep the contest inexpensive yet reach many students, we decided to take advantage of the web. Although student access was low at the time, we anticipated the growth that subsequently occurred. As a result, we structured the contest as follows:

1. All advertising is accomplished via web pages requiring very little maintenance beyond updating the results once a year. This process takes only a few hours.

2. As few libraries accessible to 6-12th graders have research quality materials, we used the summer teacher workers to digitize the Ames/Stanford summer studies and a variety of other materials. These were then placed on the web site.

3. All entries are developed by contestants on their own and sent to NASA Ames. This avoids the need to house and feed students.

4. All entries must be on paper only (no computer media) to avoid the need to decode materials in a wide variety of digital formats.

5. Although the contest is open world wide, all entries must be in English. This avoids translation expenses.

6. While entries must be related to space settlement, there are few other restrictions so there are few rules to enforce. Judging is explicitly subjective and challenges are not allowed. This substantially reduces workload.

7. Judging is always accomplished in a single day by volunteers from throughout NASA Ames. Limiting the judging to a single day makes it relatively easy for personnel to volunteer their time.

8. Prizes are limited to certificates and recognition on the web site; in addition the grand prize winner's entry is placed on the web site. The entrants are responsible for providing the entry in a standard web format.

9. Winners are invited to Ames for a tour, but at their own expense. The contest provides lunch for the students, although this is covered out-of-pocket by contest personnel when funding is particularly low.

\footnotetext{
${ }^{a}$ see www.nas.nasa.gov/About/Education/SpaceSettlement/

${ }^{\mathrm{b}}$ see www.nas.nasa.gov/About/Education/SpaceSettlement/Contest/
} 
The contest costs roughly $\$ 6 /$ entrant, mostly for personnel to receive the entries, set them up for 'judgement day,' disposing of the entries, and lunch for the tour. Increasing the number of entrants would not materially increase the cost, at least until the system for receiving entries and one-day judging are overwhelmed.

\section{Spaceset}

About the time the Ames contest was created, another annual student space settlement design contest was established, Spaceset ${ }^{\mathrm{c}}$, also known as the International Space Settlement Design Competition. This first-rate contest is designed as an industry simulation game, intended to create an experience for students similar to working in an aerospace company proposal team. Competition organizers require students to prepare designs and reports or briefings in response to a specific Requests for Proposal (RFP), and the tasks are designed to be completed by large groups of students (between 12 and 40).

Spaceset is much more labor-intensive and costly than the Ames contest. Each year, Spaceset changes the RFP for the Qualifying Competition and amends information on the website to match the particular challenge for that year. The Qualifying Competition results in 40-page documents that are judged to select student teams for Semi-Final and Finalist events. These bring between 80 and 160 students together for intense, sleep-deprived weekends of learning, designing, and presenting. The organizers prepare a program book, background materials, and a unique RFP for every event. The RFPs can be for any orbital or surface location from Earth's Moon to the asteroid belt, and presume appropriate levels of technology advances between 20 and 70 years in the future. Each "live" competition (of which there are currently four annually, and more are planned) involves on average two dozen volunteers and $\$ 20,000$ or more in costs. The organizers estimate over 1000 students annually participate in Spaceset (primarily in the qualifying rounds); most current participants are from India, with a steady flow of entries from the US and Australia, and increasing interest in Romania, Uruguay, South Africa, and other Asian countries.

Spaceset competitions are like an intellectual sporting event - intense, live, short, and with fairly specific rules. The Ames contest, by contrast, involves effectively unlimited time working at home or school with very few rules or limitations. The two contests, although conceived separately, are highly complementary. Students are often referred back and forth and, on occasion, participate in both. For example, RFP responses to Spaceset are accepted as entries to the Ames contest.

\section{Results}

Table 1 shows contest participation from 1994 to the present. We see fairly steady growth to 600 or so students per year then a jump this year. In 2006 the National Space Society (NSS) and NASA Ames signed a Space Act Agreement to support the contest. However, this had little effect on participation in 2007. In January 2008, however, the NSS began running Google ads for the contest resulting in about 2,500 clicks on the contest web site per week. This probably accounts for the increased participation this year.

About 30 teachers are involved in the contest each year until 2008 and some have made the contest a regular part of their curriculum. To help, the web site provides a full fledged space settlement curriculum plan and numerous lesson plans. A start was made to provide lesson plans tied to science standards so that teachers, or even whole schools, could use space settlement as a thematic for the entire science curriculum. Unfortunately, the contest does not have sufficient resources to complete this task. We tried having a contest for teachers to develop materials, but received no entries.

Most of the participating students are from the United States. However, every year there is substantial international participation and recently the international students have won a disproportional fraction of the prizes, especially the Grand Prize. Of particular note is the dominance of Romania since 2003. Romania isn't English speaking and is very small. Still, besides winning or tying for the Grand Prize every year from 2003-2005, in 2007 Romanians not only tied for the Grand Prize but won three of the ten first prizes. These fantastic results are in some part attributable to a single remarkable student who won Grand Prizes in 2003 and 2005 and is now attending Harvard, and a remarkable teacher who has made the contest a major activity in Romania with help from his colleagues. This does not explain everything though. The first year Romanians participated, two groups won prizes and came to NASA Ames, but they did not know of each

${ }^{\mathrm{c}}$ spaceset.org 


\begin{tabular}{|c|c|c|c|c|}
\hline Year & Submissions & Students & Teachers & Grand Prize \\
\hline 1994 & 23 & 60 & 1 & U.S. \\
\hline 1995 & 41 & 145 & 4 & U.S. \\
\hline 1996 & 42 & 142 & 7 & Argentina \\
\hline 1997 & 89 & 208 & 12 & U.S. \\
\hline 1998 & 147 & 678 & 23 & U.S. \\
\hline 1999 & 259 & 904 & 34 & U.S. \\
\hline 2000 & 151 & 569 & 31 & Ireland \\
\hline 2001 & 135 & 581 & 23 & U.S. and Austria \\
\hline 2002 & 114 & 568 & 20 & U.S. \\
\hline 2003 & 90 & 325 & 25 & Romania \\
\hline 2004 & 122 & 444 & 29 & Romania \\
\hline 2005 & 109 & 586 & 34 & Romania and India \\
\hline 2006 & 96 & 547 & 33 & U.S./Belgium \\
\hline 2007 & 109 & 601 & 33 & Romania, Uruguay and Turkey \\
\hline 2008 & 156 & 840 & 74 & Romania \\
\hline
\end{tabular}

Table 1. From small beginnings the contest has grown to involve 840 students and over 70 teachers a year, with a peak in 1999 when a popular space magazine supported the contest. The dip in 2003 was caused by a disruption in web access. The site was offline for a month, then returned on a different server. Eventually it moved to a third server and then back to the original server it started on. These moves disrupted access and reduced search engine scores. In 2001, 2005, and 2007 there were ties for the Grand Prize. In 2006 the Grand Prize Winner was a U.S. citizen attending school in Belgium.

other before arriving in California. The affinity of Romania for space settlement is somewhat inexplicable, but very real.

The appendix contains testimonials from some of the teachers and students who have participated in the contest. These show what the statistics cannot, that this contest has at times been a life-changing experience, and not just for the good students. More than one uninvolved student has turned their life around when their mind caught fire around the idea that one day they might live in space, and that their ideas are worth sharing.

As the testimonials indicate, the visit to NASA Ames is a strong incentive for participation and can be a major event in a student's development. Furthermore, the visit mixes students with NASA personnel. With the winners, this is a very good thing, even leading to collaborations and published papers. ${ }^{1-4}$ However, one year we allowed an entire class that had participated to visit NASA Ames, not limiting the visit to winners. This was a disaster. Many of the kids didn't care, wouldn't co-operate or pay attention, and even caused damage in one of the biology labs they visited. Not surprisingly, we have never been able to visit that lab again.

Missteps aside, the bottom line is that over 6,000 students have been exposed to the idea that someday we will live in space, and had an opportunity to participate in that great adventure. So far the contest has done well. However, the contest will have been a true success if, in a few decades, senior engineering and management of the team building the first space settlement are sitting around swapping stories after the preliminary design review and discover that most of them won prizes in this contest. Wouldn't that be something!

\section{Lessons Learned}

1. The web can deliver top quality educational materials world-wide at trivial cost.

2. Educational initiatives need not be costly to be effective.

3. A small fraction of students become deeply involved in these projects. For them, it can be a life-altering experience. While most of these are top-notch students, a few have been poorly motivated students 
who discovered intellectual fire for the first time.

4. Space settlement is an effective thematic for teachers and schools looking for a way to tie the curriculum into a coherent whole.

5. A visit to a NASA center is a strong inducement to participation. Visits should be limited to winners, who are nearly always well motivated.

6. It is wise to keep costs down.

7. While most entries are from the U.S., most recent grand prize winners are from overseas. Discussions with students suggest that American students are over-programmed both in school and with extracurricular activities and have little time for large projects. At least some foreign students have greater opportunities for in-depth studies not directly connected to tests.

8. Plagiarism is common, but judges can quickly determine if a suspect passage is original using simple internet searches. Some judges are very familiar with the space settlement literature and can often detect suspect passages directly. For others, radical swings in the quality of the English is a clue to plagiarism.

9. Simple high quality is not an indication of plagiarism. Some entries are almost good enough to be published with a NASA logo.

10. A single enthusiastic teacher can make a huge difference. This has been particularly apparent in Romania.

\section{Conclusion}

2008 will be the fifteenth year of the annual NASA Ames/NSS Student Space Settlement Design Contest. The contest has involved thousands of students and hundreds of teachers from around the world in the greatest peaceful adventure possible: colonization of the cosmos. One can only hope that, someday, these students have a chance to turn their dreams into reality.

\section{Appendix: Testimonials}

\section{A. Teacher Testimonials}

\section{Stephanie Passeri, Cortland Jr., Sr. High School, Cortland New York}

"No other group activity I have ever implemented has required my students to feel such a palpable sense of personal responsibility. Students repeatedly wrote about gaining self-esteem and self confidence from the experience. Some said they had learned what real commitment was all about. Before the contest they had never been interested in space technology. Now the idea of living in space seemed like a realistic goal. A number of [parents] took the time to write me letters or telephone me, thanking me for involving their children in such a unique and useful experience."

\section{Shannon Reinhold-Gee, Gordon Burnett Middle School, Seffner Florida}

"[The student managers] asked if we could hold special meetings after school. One of these managers was a young man that most teachers had become fed up with. He was lazy, uninspired, and had an attitude problem; but something changed in this young man. He became proud. He accepted the challenge. Friday's meeting was a huge success. When parents started arriving, the students were reluctant to leave. Although their meeting lasted two hours and forty-five minutes, they wanted to hold a second. [when I couldn't schedule the meeting they] redoubled their efforts in the classroom and started assigning everyone in their groups (including themselves) HOMEWORK.

I froze when I saw our schools name under the title of first place winners. I don't remember who shouted first, but the room erupted. The kids were in a celebratory mood for weeks. I overheard one student say to another, "wow, I made more friends by doing this that I would have otherwise!" I received two very special letters ... one was from one of the co-project managers. He stated that I had put a small Florida town on 
the map. My students went above and beyond because NASA sparked their curiosity. They read above their grade-level and asked and answered questions beyond their years."

\section{Ian Fogarty, Riverview High School, New Brunswick, Canada}

"It interested them enough that they worked 2-3 hrs. nightly for the entire semester on a project that incorporated English, computer science, math and physics. They proved to themselves and to the school that they can compete with the rest of the world. There tends to be a small town attitude [here] - now that they have actually traveled to NASA [the students] have taken some more challenging classes at the university and are looking at aerospace engineering as a career. The Ames Space Settlement Design Contest has made a large formal step towards developing a culture at RHS for academic excellence."

\section{B. Student Testimonials}

\section{Horia-Mihail Teodorescu, Romania, Harvard College}

"While the contest has encouraged me to learn much more about the sciences than I would have imagined, and offered an unforgettable teamwork experience, what I would consider most important is that, through its interdisciplinarity, the contest has taught me more about myself. Throught its act of teaching, it has had a major impact on my development and on my life. It has inspired me and gave me the courage to participate in small conferences and to found a student society. Through its interdisciplinarity and emphasis on creativity, the contest has shaped me in a unique manner such that I now consider it part of my identity. The contest has inspired me to continue interdisciplinary studies during the renown Summer Science Program (SSP), 2006, NM. Subsequently, the contest has shaped my interests for higher education, contributed defining my future profession, and helped me attend a top college."

\section{Moshe Looks, PhD, Software Engineer at Google}

"I participated in the 1996, 1997, and 1998 NASA Space Settlement Design Contests. In 1996 I had the pleasure of touring the NASA Ames Research Center with Mr. Al Globus. These contests, along with the opportunity to observe space science first-hand, were invaluable experiences. They have influenced my ambitions and choice of career, as well as my study habits, more than any junior high school or high school class that I took. The contests encourage students to think big, but in a critical way. A successful entry requires seriously hitting the books, the first time I was forced to do so. Beyond directly spotlighting the importance of space settlement and of NASA, I am certain that the contests have had a ripple effect of attracting young minds to ambitious projects across all fields of science and engineering."

\section{Anguel Alexiev}

"Although this e-mail comes to you a bit late, I nevertheless wanted to thank you for the influence the Space Settlement Design competition has had on me. Of course, I was not aware of this having gone through a great deal in the past two years. The competition is very different from anything else offered in high school. The synthesis of a vivid imagination and an analytical understanding is much underrated in our cirruculum. One cannot start without first conjuring the preliminary ideas, and only then working on the science behind making those ideas work. When I took a class in organic chemistry at Harvard Summer School last year, it was impossible to remember the myriad reactions without visualizing molecules colliding with each other, exchanging electrons, morphing into other molecules, etc. Having done that, the class was surprisingly easy for me (I aced it). I also wrote about the overlap of imagination and understanding in my application essay to Caltech, which accepted me in December."

\section{Dan Costea, Romania, ESA Fluorinert (FC-72) in Micro-gravity experiment team}

"The competition really helped me a lot to enlarge my views. That was the moment when I received the real international feeling; when I felt I wanted to do something more. It helped me to get a lot of self-confidence, to learn how to deal with research a bit, to lead a team and to deal with the media. I also enjoyed that place and those people that I met at Ames." 


\section{Vrinda Aggarwal, India}

"When I found this competition on the internet I was overjoyed. I saw this competition as my first step towards my dream of becoming an aerospace engineer. Firstly, it was tough to find members for the team. I asked many friends but no one was interested. Then I asked those people to be in the team whom I didn't know properly but knew they would be interested. I don't regret my decision and the proof is of our winning honourable mention in 2005. That moment was just amazing and I was very happy. But we were not satisfied with this and again sent the project in 2006 and won 2nd prize. and finally our trip to NASA was just out of the world. That one day was great......sitting in the NASA cafe and having lunch was unexpected and I never dreamt of it. Thank you so much for making my that day so different and wonderful.

This project me gave me a wonderful friend, Nivedita with whom I can share all my secrets. During the making of the project, all of us fought amongst each other....... respected each others thoughts......had wonderful discussions.....learnt a lot. The whole experience was amazing and unforgettable."

\section{Nittin Arora, India, Georgia Institute of Technology}

"Space science and technology has always fascinated me from a very early age; hence I was very interested in working for NASA, or be related to NASA in some sort. This dream of mine could never have come true if it wasnt for the NASA Space Settlement Design competition. It not only made me realize my dream but also the experience and involvement in the competition motivated me to work with Mr. Al Globus on a new space colony design. Furthermore this helped me getting admission in a top grad school, Georgia Institute of Technology. Apart from apparent great benefit to my career, the competition also boosted my self confidence and made me realize the values to be gained as a researcher. I really thank the people in NASA who made the competition a success and I hope it would continue to motivate students like me to achieve in life what they really dream of."

\section{Romina Muniz, Uruguay}

"From the moment I received the call from my school, informing me I was chosen to be a part of the NASA competition, I felt the opportunity to confront so many exciting challenges at my age was an incentive all in itself. As our project advanced, I realized our work had grown into a truly good project with merit. When we learned we won first place in the contest, we were grateful for all the hours of hard work, exchanging of ideas and dedication we had put forth. From that moment we knew the contest had been an excellent vehicle for learning. Not only had it enriched us as students and as individuals, it was an educational experience that could be applied on a broader national level. As if it were offered in direct response to our dedication and hard work we had the opportunity to visit what we considered to be an unattainable goal; visiting NASA. It was upon reaching this goal that I realized failure would not be an option in my life and that I would always go for it...

To date, this has been the most notable change in my life, because this experience has gotten me interested in reaching a higher understanding of chemistry, physics, mathematics and everything that had previously been a mystery to me, simply because we had never been aware of their existence. It is clear to me that as an individual I have been enriched. Now I know that dreams need only to be combined with work and dedication in order to make them a reality and benefit for all. "

\section{Felipe Juda, Argentina}

"Hi, my name is Felipe Juda. You may not remember me but I surely do not forget the day we went to visit NASA Ames Research Center. To give you I better idea of who I am, I was with a group of students from Argentina which participated in a NASA Contest in 1996 where the objective was to design a Space Colony (our teachers were Gabriel Rshaid and Victor Capeluto).

I just wanted to thank you for bringing a whole new World to me by showing us NASA Ames Research Center's facilities. That was an experience that I will never forget, just in one day, you opened our minds towards the future. Thank you very much for your kind gesture." 


\section{Olteanu Oana-Elisa, Romania}

"My name is Olteanu Oana-Elisa and I am a Romanian citizen. I live in a village, called Topraisar, which is situated at a distance of $30 \mathrm{~km}$ from Constanta City. My work at the Apis project included some chapters for which was necessary a profound study of information about the placement of the space settlement, creation of the artificial gravity and others. Nevertheless, it was something that I created based on my knowledge and imagination and that is the external and internal structure of the space settlement. Remembering the holidays spent to my grand parents, especially the colonies of bees, I thought that people, in their new home, would survive only having a good organization and being united like bees. Therefore, I came up with the idea to use the honeycomb in the shape of the space settlement, structure that has a whole series of advantages, and I made a sketch with the shape of the space settlement. Participating at NASA Space Settlement Design Contest determined me, to apply to an abroad university. The grand prize won at this challenging contest is very important to me because it consolidated my self-confidence but also for the fact that I showed to the other children from my village, that exists an alternative for their future. A real example is my neighbor, a little boy of 8 years old that told to his mother he wants to study to be like me. In this way, I gave them and to me a hope, a hope that when you want something and you work hardly you will obtain results no matter the occurred obstacles. I want to thank NASA for offering students worldwide the opportunity to challenge their imagination and knowledge in trying to discover and understand the greatness of the Universe; or in the words of Star Treks Capitan Picard, to boldly go where no one has gone before.

\section{Acknowledgments}

Thanks to Tugrul Sezen for helping found the contest. Thanks to Anita Gale, founder of Spaceset, for encouragement and valuable conversations. Thanks to Joey Mercer, Jeff Homola and Bonnie Klein for reviewing drafts. Special thanks to NASA Ames, the National Space Society, and Ralston Middle School, Belmont, California for hosting versions of the web site.

\section{References}

\footnotetext{
${ }^{1}$ Teodorescu, H. M. and Globus, A., "Radiation Passive Shield Analysis and Design for Space Applications," SAE 2005 Transactions Journal of Aerospace, , No. 2005-01-2835, March 2005, pp. 179-188.

${ }^{2}$ Bajoria, A., Arora, N., and Globus, A., "Kalpana One: A New Space Colony Design," 10th ASCE Aerospace Divsion International Conference on Engineering, Construction and Operations in Challenging Environments, Houston, Texas, March 2006.

${ }^{3}$ Arora, N., Bajoria, A., and Globus, A., "Kalpana One: Analysis and Design of a Space Colony," 47th Structures, Structural Dynamics and Materials Conference, No. AIAA-2006-2183, AIAA, ASME, ASCE, AHS, ASC, May 2006.

${ }^{4}$ Globus, A., Bajoria, A., and Arora, N., "Kalpana One: A New Orbital Space Colony Design," 25th Internatioal Space Development Conference, National Space Society and the Planetary Society, May 2006.

${ }^{5}$ Johnson, R. and Holbrow, C., "Space Settlements: A Design Study," Tech. Rep. SP-413, NASA, 1975.

${ }^{6}$ ONeill, G. K., Space Resources and Space Settlements - NASA SP-428, NASA, 1977.
} 